\title{
Education for life or life-long education?
}

\author{
Louis D. Smullin \\ Massachusetts Institute of Technology, Cambridge, MA, U.S.A.
}

\begin{abstract}
Historically, people learned skills that lasted for their lifetime. This was «education for life». In the modern technical and scientific world, things change so rapidly that a professional must continuously learn new material. This is «life-long education». Technological advances require significant changes the electrical engineering curriculum. Studies of vacuum tubes and transformers have given way to studies of control theory, VSLI chips, semiconductor technology and lasers. An electrical engineer can not expect to master all aspects of the field within four or even eight years of study. Continuing education has become part of an engineering career.
\end{abstract}

Key words education - electrical engineering

In the fall of 1961, I received a call from the headquarters of the Research Laboratory of Electronics at MIT. They wanted to know if my group could use a physics post-doc, an Italian who had just finished a job in Canada. As it happened, I had recently convinced the laboratory director that it was possible to shine a laser at the moon, and to detect the reflection. The MIT Lincoln Laboratory had built a 48" reflecting telescope for NASA that had to be delivered by June, 1961; until then we were free to use it. The Raytheon Company had agreed to provide us with a $50 \mathrm{~J}$ ruby laser. These were the basic elements that we needed; but they had to be integrated into a working system, and I needed help! The help was Giorgio Fiocco. Between then and the following May, there were long hours of work, until we were ready for our first attempt. We worked for several days to assemble all of the equipment at the telescope site. When we finally were ready, we opened the roof of the telescope

Mailing address: Prof. Louis D. Smullin, Massachusetts Institute of Technology, 77 Massachusetts Avenue, Cambridge, MA 02139-4307, U.S.A. building only to see a sky full of big snow flakes, in May! We had to wait two weeks until the next half moon reappeared, without snow. We wanted the half moon because it seemed to be the best compromise against earth-shine, that would obscure the reflected laser light. That was the beginning of a long friendship between my family and his. Fiocco told me about the mysterious noctilucent clouds that appeared over the arctic regions, and that was his next challenge - to design and build a portable system that he could take to Northern Norway. As far as I can tell, he is the same smiling (but now white haired), bouncy guy that we met 40 years ago. I feel privileged to be invited to speak at this event that honors his career.

A profession is a career in which a practitioner is expected to have a mastery of certain basic skills and arts. In the old days of guilds and apprenticeships one learned by working for a recognized master of the specific craft: medicine, law, masonry, blacksmithing, etc. The apprentice was expected to learn the techniques and practices of his trade, as well as its culture, specific technical terms, how to deal with clients, etc. The rates of change of various arts and technologies were slow compared to the working life of an individual, so that it was meaningful to think of «education for life». Within the last half-century, or so, things have begun to change 
drastically, so that the utility of learned material begins to fade with a half-life of 5 or 10 years, depending on the subject.

In 19th century the universities began to expand their educational roles beyond training for the church, and they began to offer educational programs in the law, medicine, the sciences, and engineering. Thus were born the academic professions. Then governments took on the job of defining who was entrusted to practice, by issuing licenses. There are scheduled examinations for medicine, for law, for licensed engineers, etc. Today, a licensed electrical engineer would be expected to display a working knowledge of motors, generators, and power distribution systems. But he is not likely to be tested on his knowledge of VLSI chips, or on the fine points of optical fiber systems. Today, in the US most engineers are «unlicensed» except for a small number of consulting engineers. Most engineers work for an employer, or for a firm, that has the responsibility of weeding out the incompetents. The public is protected by its ability to sue the firm for incompetence or shoddy practices, or to not purchase its products.

Our education system is an extension of that of many other warm-blooded animals: birds, apes, whales, etc. The young animal is kept close to the mother or the group (herd) where it learns the necessary skills for survival (flying, hunting, communication). Today the first 20 years of a person's life are spent in learning what to do in the next 40 or 50 years. For physicians or PhDs we may use up the first 30 years. Clearly, we have reached some sort of economic limit to how much time can be devoted to education before one begins to participate in the activities of the community. This is what I call «Education for Life». But in our technical and scientific world, things change so rapidly that a «professional» must continually learn (or study) new material in order to be productive and competitive. This activity we call «Life Long Learning». Learning is hard work, and it uses up time and energy that might be more pleasantly spent. We have all observed young boys devoting hours to learning a particular basketball or football maneuver with no supervisor or teacher watching them, they know these are important to learn and they know when their performance is satisfactory. But this sort of focussed learning is less common among adults - there are too many other competing demands on one's time.

There is a small number of self educated engineers. The rest attend academic institutions of some sort, and study electrical, mechanical or some sort of engineering in a structured environment. The institution is accredited to award appropriate degrees to students who have completed an accredited curriculum. The curriculum is accredited by examining how much time each student is required to spend on a list of «important» subjects. The facilities (libraries, laboratories, etc.) are examined. The teaching staff is examined for specific competencies, and syllabi are examined along with typical homeworks and examinations. The whole process of accreditation is to assure that a student will be able to do the work of an engineer. An electrical engineer will not be expected to know much about reinforced concrete construction; but he may reasonably be expected to know something about electric motor design, linear electric circuits, digital circuitry, design of a web page, communication systems, control systems, programming languages, lasers and optical fiber optical systems. Suddenly it is not reasonable to expect him/her to be skilled in all these areas.

As we began to expand the number of computer specialists among our professors, about 25 years ago, our EE department changed its name to EECS (Electrical Engineering and Computer Science). Since then many other departments have done the same. Each having two or even three separate curricula. We are now required to be separately accredited in EE and in CS. A few years ago, we decided that 4 years was too short a time for a first professional degree. We now award a first professional degree in 5 years, the MEng (Master of Engineering). This provides a miniscule 20\% improvement for a field that seems to have its own Moore's law for adding new subjects and disciplines under its umbrella.

We begin with some constraints: most of our students begin their university study at about age 18. The Bachelor's degree is awarded after about four years. Most engineering students expect to finish their studies after about 4 years, and then go to work at about age 22. A smaller number stay for an MS degree, and an even smaller number stay for a Doctoral degree. 
There is no reason to believe that the mental powers of students today are any greater than they were, say, 100 years go. I was a student in the 1930s. We thought that we worked fairly hard at our studies, today's students think the same, «Tech is Hell» is their description of MIT. As time has progressed, so has the domain of EE. As new fields emerge, we have had to add new material to the curriculum. The choices have to be made: what old material can be eliminated or covered more lightly? The years after World War II saw the introduction into our curricula of hollow wave guides and of microwaves, followed by communication theory, control theory, transistors, computers and their languages, VLSI chips with more than a million interconnected elements, semiconductor technology, optical waveguides. Lasers are imbedded in the whole curriculum, quantum computing and entangled states are on the near horizon, and we may have to learn how to design and fabricate digital circuits made from organic polymers. Study of the detailed design of motor armatures is a thing of the past. Vacuum tubes are gone, so is illumination engineering. The detailed study of transformers has vanished but new applications of spin phenomena are growing. What else can we eliminate from the curriculum to make room? I can claim a sort of priority: in 1938 Claude Shannon tried to explain to me his now-famous Master's thesis on switching theory. Later on, in about 1949, Charles Townes tried to explain his microwave maser. Finally, in about 1980 young Stephen Wiesner tried to explain his ideas about quantum communication systems and entangled states. In none of these cases was my educational background wide enough for me to even grasp what they were trying to tell me.

Until recently, I felt that there was a culture that defined our profession. If I said «matched impedances» to a colleague, I knew the image it would evoke. Similarly with «Thevenin generator». In 1936, I would have drawn a blank if I were tested with «Boolean logic» or «stimulated emission». Although I had studied a good course in vacuum tubes, «velocity modulation», or «bunching», or «holes» would have meant nothing. Several years ago, I made an informal survey of the research topics of our EECS faculty and their graduate students. The result was that less than $20 \%$ required a deep understanding of electricity, as I had known it. They were concerned with control theory, system theory, communications and coding, computer systems and languages, quantum theory, queuing theory, and neuro-physiology. None of these required an explicit knowledge of electricity (my shorthand for this was «Ohm's Law»)

When I was younger, I used to read the German technical literature. They defined two domains of electrical engineering: STARKSTROM, and SCHWACHSTROM: strong current (power), and weak current (radio and telephony). Today, we must add a third category, KEINSTROM, no current (everything else).

A culture implies a shared set of beliefs and images. In literature I used to think that a quotation from Longfellow's «Hiawatha» (by the shores of gitchi goomy, by the shining big sea waters, stood the wigam) would elicit a response from an educated (US) person. My colleague Roberto Fano used to think that he could use a similar test by rolling off the first few cantos of the Inferno. Things have changed! The classics of literature have no «practical» value; but the classics of electricity are what hold our society together. The lights, phones, elevators, radio and $\mathrm{TV}$, and air conditioners are absolute necessities. Today, there is a movement among conservative educators to restore the classics of literature to their once held central position. Whether or not this is a good thing, I have no opinion. I am no expert. There is no similar movement to restore echt electricity to its old position of primacy. It is true that education for electrical systems have to be redesigned and rebuilt. A great deal of the old knowledge has been captured in the literature and in specialized computer programs and handbooks, so that a smart but ignorant electrical engineer can learn what is expected of him. For now, at least, a relatively small number of experts can cope with the situation. Very few of our present graduates would be able to recreate our present technical society if they were cast off on a dessert island like Robinson Crusoe. There is no way that within 4 or even 8 years of study, that an engineer can be educated for life. Continuing education has become part of an engineering career. Its format will vary. For some, reading the technical journals will 
help. For many others a more formal and structured way of learning works better. The mores of the work environment will have to change so that there is time and the opportunity for such study. This can be in the form of a short series of lectures (a few days), or even a longer full course for a semester is better suited. The important thing is knowing how to learn.

Students are free agents who can choose to study whatever interests or excites them. There is little doubt that the newspaper stories of web billionaires before they are 30 years old is part of the attraction of computer science. For those students, the importance of learning the fine points of linear circuit theory corresponds to an English speaking student struggling with the complexities of the ablative case. It is a worldwide phenomenon that computer science is the most attractive of the engineering studies. But it is also true that the lure of new «hot» research fields is something that professors find hard to resist, and that few administrators of funding agencies can resist bragging about.

What to do? Moore's law speaks about the doubling time of VLSI capabilities. The domain of EECS seems to be subject to the same expansion rate. We can not keep people in school forever. They have to learn some of today's relevant facts and technologies so that they can begin a job. However, the growth of continuing education seems to be a way of approximating that goal. There was a time when the problem could be handled by focusing on the «basics»: math, physics, chemistry, biology. But even that has become difficult to accomplish within 4 or 5 years of formal education. We might Balkanize the field even more than it is today. The IEEE, today, publishes more than 40 professional journals that cater to various subspecialties. How can a young person decide which of these routes to follow? There was a smug belief that «an electrical engineer can learn anything». To the extent that it was true, it was probably because he (she) had been forced to learn «how to learn». In an old copy of mine of the Abraham and Becker book on electromagnetic theory, there was an exhortation on the first page to really do the problems, and not to pretend that you «understand» the material. It still seems so today, that problem sets are what fix ideas in one's mind. The process of studying a difficult field teaches one how to learn, and it makes continuing education possible. Maybe the trick is this: given a choice of curricula, a student will choose what excites him/her, and will accept the inclusion of difficult material, if it seems «relevant» to the objective of the course. (Today, many computer science students are impatient with having to study linear circuit theory, but they will work hard at what they consider relevant.) If later in his career, he suddenly is confronted by switching power supplies, or some other idea or technology, he will be able to read the literature, and to proceed, (we hope!).

In closing, let me remind you that the career of Giorgio Fiocco has been one of life-long learning. When he first told me about noctilucent clouds, the «ozone hole» was not even a concept; and setting up facilities in Antarctica instead of in Norway was really a crazy idea. But thanks to his work, we now know when to wear a sun hat and what number sunscreen lotion to use. 